\title{
Identifikasi Embrio dalam Telur Berbasis Image Processing
}

\author{
Nur Farida Arini ${ }^{1}$, Achmad Ubaidillah ${ }^{1}$, Kunto Aji Wibisono ${ }^{1}$, Miftachul Ulum ${ }^{1}$ \\ ${ }^{1}$ Program Studi S1 Teknik Elektro, Universitas Trunojoyo Madura \\ J1. Raya Telang Perumahan Telang Indah Kamal Bangkalan Jawa Timur 69162 \\ E-mail: nfaridaarini@gmail.com)
}

\begin{abstract}
Abstract - One of ways to increase the success of hatching eggs is by selecting and separating the eggs embryonated (fertile) with eggs are not embryonated (infertile) by way of observation (candling). This system utilizes digital image processing as an identification process. By this system, it is expected that the identification results will be more accurate results than conventional monitoring, so as to increase the results of hatching. This system utilizes a flashlight as a medium, so that the egg's internal condition can be seen which then takes pictures by the webcam. After that the digital image processing is done by converting the original image $(R G B)$ to binary image by providing a thresholding value $(T)$, the $T$ value is very influential in the next image processing, opening and closing, thinning the image (thinning), and contour detection. Then from the final process of contour detection produces the number of detection of blood vessels that are considered as embryos as a determinant of the outcome category of identification. From the experiments carried out the percentage of conformity between the original condition of the egg with the results obtained in the system that is $88.88 \%$, in determining the yield category (fertile/infertile) with an error of $11.12 \%$. For the suitability of the estimated percentage of hatchlings themselves have a success of $61.11 \%$ with an error of $38.89 \%$. These results are influenced by many factors like the condition of the eggs and supporting devices in the system.
\end{abstract}

Keywords : fertile, infertile, candling, image processing, thresholding.

Copyright (ㅇ 2019 Universitas Muhammadiyah Jember.

\begin{abstract}
ABSTRAK
Abstrak - Salah satu cara untuk meningkatkan keberhasilan pada penetasan telur adalah dengan memilih dan memisahkan antara telur berembrio (fertil) dengan telur yang tidak berembrio (infertil) dengan cara peneropongan (candling). Pada sistem ini memanfaatkan pengolahan citra digital sebagai proses identifikasi. Dengan adanya sistem ini diharapkan hasil identifikasi memiliki hasil yang lebih akurat dibanding peneropongan secara manual, sehingga dapat meningkatkan hasil penetasan. Sistem ini memanfaatkan senter sebagai media agar kondisi internal telur dapat terlihat yang kemudian dilakukan pengambilan gambar oleh webcam. Setelah itu di lakukanlah proses pengolahan citra digital dengan pengkonversian citra asli (RGB) ke citra biner dengan memberikan nilai thresholding (T), nilai T tersebut sangat berpengaruh pada proses pengolahan citra selanjutnya, opening dan closing, penipisan gambar (thinning), dan deteksi kontur. Kemudian dari proses akhir deteksi kontur tersebut menghasilkan jumlah pendeteksian pembuluh darah yang dianggap sebagai embrio sebagai penentu kategori hasil dari identifikasi. Dari percobaan yang dilakukan memiliki persentase kesesuaian antara kondisi asli telur dengan hasil yang diperoleh pada sistem yakni 88,88 \%, pada penentuan kategori hasil (fertil/infertil) dengan error sebesar $11,12 \%$. Untuk kesesuaian perkiraan persentase tetas sendiri memiliki keberhasilan sebesar $61.11 \%$ dengan error 38,89\%. Hasil tersebut dipengaruhi oleh banyak faktor seperti kondisi telur dan perangkat pendukung pada sistem.
\end{abstract}

Kata kunci: fertil, infertil, candling, image processing, thresholding

Copyright (C) 2019 Universitas Muhammadiyah Jember.

\section{PENDAHULUAN}

Untuk meningkatkan prosentase penetasan telur dibutuhkan beberapa penanganan, diantaranya adalah memisahkan telur yang dibuahi dengan yang tidak dibuahi. Telur yang dibuahi memiliki ciri terdapat embrio didalamnya, sedangkan telur yang tidak mengalami pembuahan akan terlihat kosong. Telur yang terdapat embrio di dalamnya diletakkan di tempat khusus untuk proses penetasan. Sedangkan telur kosong 
dapat segera dipisahkan untuk keperluan lain seperti dikonsumsi. Untuk mengetahui fertilitas pada telur maka dilakukan proses peneropongan (candling).

Berdasarkan uraian di atas, maka pembuatan sistem identifikasi telur berbasis image processing ini dilakukan. Selain untuk penerapan ilmu yang didapat pada masa studi, sistem ini dibuat untuk mengikuti perkembangan teknologi yang berjalan pesat. Sehingga dapat membuat proses peneropongan secara otomatis. Sistem ini memodifikasi dari sistem peneropongan secara manual. Penggunaan konveyor sebagai media pengganti tangan diharapkan mampu meminimalisir bakteri yang menempel pada telur, sehingga dapat meningkatkan persentase penetasan. Kemudian sistem ini juga memanfaatkan webcam sebagai media pengambilan citra internal telur sebelum diproses pada pengolahan citra digital.

\section{KAJIAN PUSTAKA DAN PENGEMBANGAN HIPOTESIS}

Pembuatan sistem ini tidak luput dari pengambilan dan perbandingan referensi dari penelitianpenelitian terdahulu. Dari penelitian Muhammad zaen nawawi, dkk (2015) dengan "Klasifikasi telur fertil dan infertil menggunakan jaringan saraf tiruan multilayer perceptron berdasarkan ekstraksi fitur warna dan bentuk". Pada penelitian tersebut membahas tentang pengklasifikasian fertlitilitas telur berdasarkan bentuk dan warna telur. Shape index, roundness dan elongation diekstraksi dari bentuk telur, sedangkan nilai rata-rata hue, saturation dan intensitas diekstraksi dari warna telur. Nilai laju pembelajaran yang digunakan adalah 0.0005 dan momentum sebesar 0.02 untuk mencapai akurasi yang tinggi [1].

Kemudian pada penelitian milik Soffan saifullah, dkk (2017) dengan judul "Analisis ekstrak ciri fertilitas telur ayam kampung dengan grey level cooccurence matrix", dalam penelitiannya ini mengidentifikasi fertilitas telur ayam menggunakan GLCM dan beberapa parameter utama seperti ASM (Angular Second Moment), kontras, korelasi, varians, IDM (Inverse Difference Moment), dan entropy. Masing-masing parameter tersebut akan memberikan nilai yang berbeda dalam telur fertile dan infertile [2]. Dan masih terdapat beberapa penelitian lainnya yang menjadi referensi. Kemudian berikut beberapa kajian pustaka yang digunakan pada penelitian ini.

\section{a. Fertilitas Telur}

Fertilitas (kesuburan) telur merupakan sebuah indikator ada tidaknya embrio yang tumbuh dalam telur tersebut. Kemudian, untuk melihat fertilitas pada sebuah telur dilakukan dengan cara peneropongan (candling), dimana hal tersebut dilakukan menggunakan cahaya lampu atau senter untuk melihat perkembangan embrio pada telur.

\section{b. Operasi Pengambangan atau Thresholding (T)}

Operasi thresholding digunakan untuk konversi ke citra biner atau untuk segmentasi citra. Segmentasi citra adalah proses pengolahan citra yang bertujuan memisahkan wilayah (region) objek dengan wilayah latar belakang agar objek mudah dianalisis dalam rangka mengenali objek yang banyak melibatkan persepsi visual [3]. Pada umumnya nilai $\mathrm{T}$ dihitung dengan menggunakan persamaan berikut.

$$
\mathrm{T}=\text { fmaks }+ \text { fmin } / 2
$$

Dimana fmaks adalah nilai intensitas maksimum pada citra dan fmin adalah nilai intensitas minimum pada citra. Jika $\mathrm{f}(\mathrm{x}, \mathrm{y})$ adalah nilai intensitas piksel pada posisi $(\mathrm{x}, \mathrm{y})$ maka piksel tersebut diganti putih atau hitam tergantung dengan kondisi berikut seperti pada persamaan 2 dan 3 di bawah ini.

$$
\begin{aligned}
& f(x, y)=255, \text { jika } f(x, y) \geq T \\
& f(x, y)=0, \text { jika } f(x, y)<T
\end{aligned}
$$

\section{c. Pengolahan Citra}

Pengolahan citra digital adalah sebuah disiplin ilmu yang mempelajari tentang teknik-teknik mengolah citra. Citra yang dimaksud disina adalah gambar diam (foto) maupun gambar bergerak (yang berasal dari webcam). Sedangkan digital disini mempunyai maksud bahwa pengolahan citra atau gambar dilakukan secara digital menggunakan komputer[4]. Pada aplikasi pengolahan citra digital pada umumnya dibagi menjadi 3 yakni RGB, black and white, dan citra biner. Pada sistem ini menggunakan beberapa operasi pengolahan citra seperti opening dan closing, penipisan (thinning), dan kontur. 


\section{d. Operasi morfologi opening dan closing}

Morfologi merupakan teknik pengolahan citra yang bertujuan untuk mengubah bentuk objek pada citra asli [5]. Opening pada umumnya digunakan sebagai penghilang objek-objek kecil dan memberi kesan smooth pada citra yang memiliki ukuran besar. Sedangkan closing memiliki fungsi untuk mengisi lubang kecil pada objek dan menggabungkan objek yang saling berdekatan.

\section{e. Image Thinning}

Thinning merupakan metode yang digunakan untuk skeletonizing yang slah satu penggunaannya adalah dalam aplikasi pattern recognition. Terdapat cukup banyak algoritma untuk image thinning dengan tingkat kompleksitas, efisiensi, dan akurasi yang berbeda-beda. Citra yang digunakan adalah citra biner, jika citra itu merupakan suatu citra grayscale, biasanya dilakukan thresholding terlebih dahulu sedemikian rupa sehingga citra tersebut menjadi citra biner [6]. Algoritma image thinning yang banyak digunakan adalah zhang suen dan stentiford.

\section{f. Konveyor}

Konveyor merupakan peralatan yang digunakan untuk memindahkan suatu material dari satu tempat ke tempat lain. Konveyor berguna untuk memobilisasi benda-benda dengan jumlah yang banyak. Konveyor pada umumnya digunakan di berbagai macam jenis industri, diantaranya pertambangan, otomotif, pertanian, komputer, elektronika, proses pangan, proses pembotolan, kimia, dan banyak bidang lainnya. Untuk mini konveyor yang diunakan pada sistem ini menggunakan mikrokontroer ATmega16, motor dc, serta dilengkapi dengan sensor proximity inframerah.

\section{METODE PENELITIAN}

Pengumpulan sumber referensi yang berkaitan dengan penelitian baik melalui jurnal, buku, ataupun media elektronik merupakan langkah awal pada pembuatan sistem. Selanjutnya yakni perancangan hardware dan software, dimana pada hardware ialah mini konveyor yang dilengkapi sensor dan webcam, kemudian pada software meliputi program pengolahan citra digital. Tahap selanjutnya yakni pengujian dan pengumpulan data hasil percobaan. Dari hasil yang diperoleh, langkah berikutnya adalah menganalisanya untuk mendapatkan kesimpulan bahkan berguna untuk mengetahui kelebihan dan kelemahan sistem yang telah dibuat. Setelah diketahui informasi mengenai hal tersebut, diharapkan mampu menjadi masukan yang lebih baik untuk pengembangan sistem selanjutnya.

\section{HASIL DAN PEMBAHASAN}

\subsection{Hasil Uji Konveyor}

Berikut merupakan blok koneksi dari perangkat keras yang diaplikasikan pada konveyor ditunjukkan pada gambar 1.

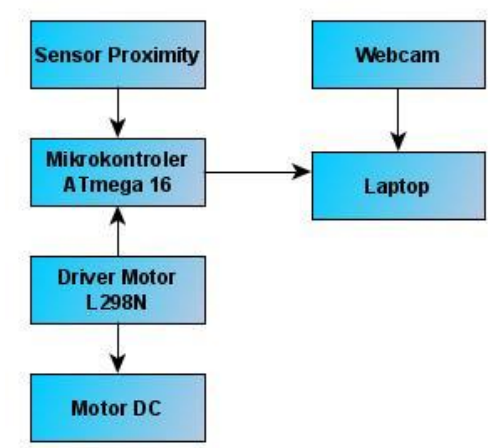

Gambar 1. Blok Koneksi Hardware

Cara kerja dari sistem ini sendiri ialah telur sebagai data uji diletakkan pada alas konveyor yang kemudian bergerak menuju box kayu sebagai ruang gelap. Di dalam box tersebut terdapat senter sebagai sumber cahaya, sensor sebagai pendeteksi objek, dan webcam sebagai pengambil citra internal telur. Ketika telur terdeteksi oleh sensor inframerah, maka mikrikontroler akan mengirimkan perintah pada driver motor L298N untuk mengubah kondisi motor dc dari 255 (kecepatan penuh) menjadi 0 (berhenti) dengan delay waktu yang telah ditentukan. Setelah itu webcam akan melakukan pengambilan gambar internal telur melalui GUI yang telah dibuat pada aplikasi delphi. Berikut bentuk fisik dari konveyor yang digunakan. 


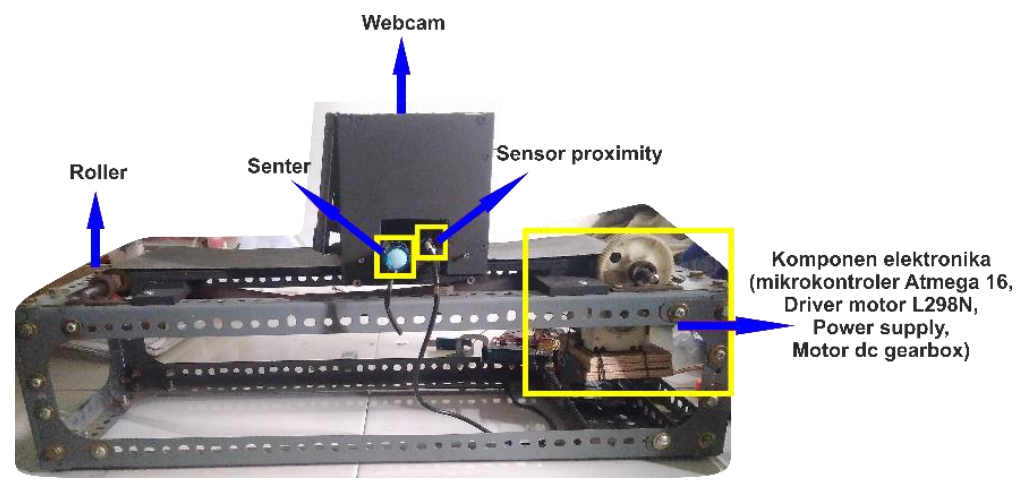

Gambar 2. Bentuk Fisik Konveyor

\subsection{Hasil Uji Pengolahan Citra Digital}

Pada proses pengolahan citra digital sendiri meliputi beberapa proses yakni operasi thresholding, opening dan closing, penipisan (image thinning), dan deteksi kontur. Proses segmentasi menggunakan thresholding ( $\mathrm{T}$ ) yang dinilai sangat penting, karena operasi ini akan memisahkan embrio yang terdeteksi dengan background. Selanjutnya, untuk operasi opening dan closing sendiri bertujuan sebagai filter atau pembuang noise agar mendapatkan hasil yang maksimal. Kemudian penipisan (thinning) berguna untuk menghilangkan piksel tertentu pada objek menjadi hanya satu piksel. Untuk kontur sendiri pada sistem ini berguna sebagai penanda objek yang dianggap sebagai pembuluh darah atau embrio yang ditandai dengan kotak kecil. Dari jumlah tanda tersebut digunakan sebagai parameter penentu hasil kategori telur (fertil/infertil) dan perkiraan persentase tetasnya. Hasil dari proses tersebut dapat dilihat pada tabel hasil pengujian identifikasi telur pada tabel 2 bagian hasil. Namun sebelumnya di bawah ini ditunjukkan hasil dari pengujian segmentasi citra menggunakan metode thresholding dengan input nilai T yang berbeda-beda seperti pada tabel 1 berikut.

Tabel 1. Hasil Pengujian Thresholding (T)

\begin{tabular}{cccc}
\hline Nomor & Nilai & Citra asli & Hasil \\
\hline 1 & 10 & & \\
\hline 2 & & & \\
\hline 3 & 11 & & \\
\hline 4 & 120 & & \\
\hline 5 & 25 & & \\
\hline 6 & & & - \\
\hline
\end{tabular}

Dari hasil di atas dapat disimpulkan bahwa semakin besar nilai threshold yang diberikan, maka hasil yang diperoleh citra akan mendekati kondisi 255 (putih). Jadi hal tersebut sesuai dengan teori thresholding dan persamaanya seperti yang digunakan pada kajian pustaka di atas [3].

Kemudian berikut ini merupakan hasil pengujian yang telah dilakukan pada beberapa sampel telur dengan kondisi yang berbeda-beda. Hasil pengujian ditunjukkan pada tabel 2 di bawah ini. 
Tabel 2. Hasil Pengujian Identifikasi Telur

\begin{tabular}{|c|c|c|c|c|}
\hline Nomor & Nilai $T$ & Citra asli & Citra biner & Hasil \\
\hline 1 & 55 & & & \\
\hline 2 & 55 & & & \\
\hline 3 & 45 & & & $4 \pi$ \\
\hline 4 & 65 & & & \\
\hline 5 & 55 & & & \\
\hline
\end{tabular}

Pada tabel di atas menunjukkan citra asli, citra biner, dan hasil. Untuk citra biner diperoleh dengan proses segmentasi citra yakni metode image thresholding. Dengan menggunakan nilai threshold (T) tertentu maka akan menghasilkan citra dalam bentuk hitam putih, yang mana objek dalam hal ini merupakan embrio telur akan terpisah dari backgroud. Kemudian pada hasil sendiri merupakan citra biner yang telah melewati proses opening dan closing, penipisan (thinning), dan deteksi kontur yang mana objek yang dianggap sebagai pembuluh darah ditandai dengan kotak kecil sebagai parameter penentu kategori hasil telur dan perkiraan persentase tetasnya.

\section{a. Hasil Uji Coba Pertama}

Di bawah ini merupakan hasil uji coba pemrosesan citra telur pertama dengan nilai T sebesar 55.

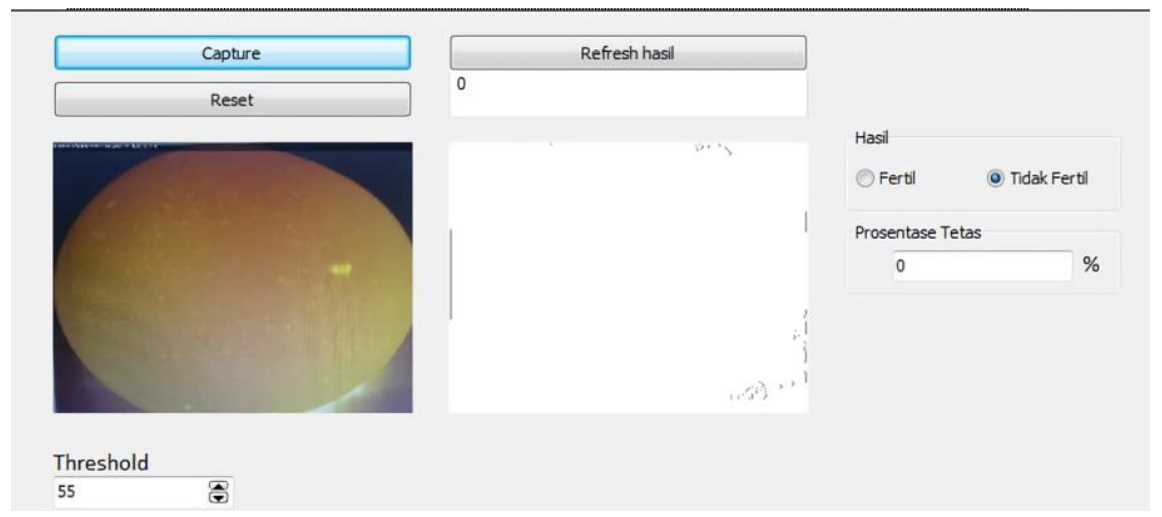

Gambar 3. Tampilan hasil pada GUI

Gambar di atas merupakan hasil pemrosesan identifikasi pada tampilan GUI. Dari hasil tersebut dapat diketahui bahwa kondisi asli telur yakni infertil (kosong), dengan input T sebesar 55 hasil yang diperoleh sesuai antara sistem dengan kondisi telur sebenarnya. Hal tersebut diketahui dari tidak adanya embrio yang terdeteksi oleh sistem. 


\section{b. Hasil Uji Coba Kedua}

Di bawah ini merupakan hasil pemrosesan citra telur pada percobaan kedua dengan $\mathrm{T}=55$.

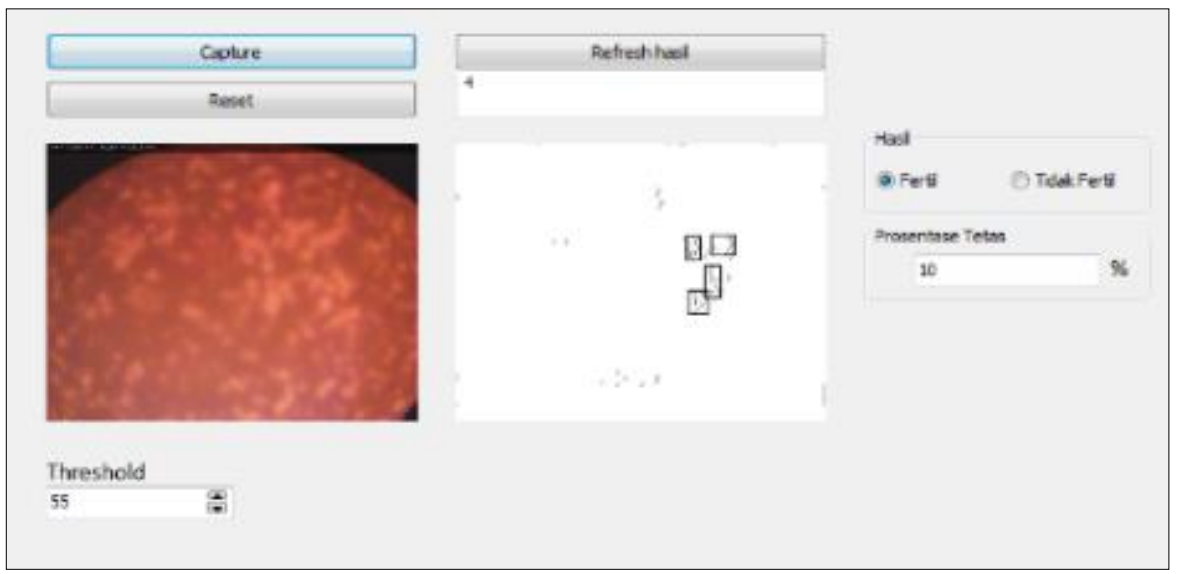

Gambar 4. Tampilan hasil pada GUI

Dari hasil yang ditampilkan pada GUI dapat diketahui bahwa kondisi telur yang sebenarnya adalah infertil (kosong). Namun pada sistem mengidentifikasi bahwa telur tersebut fertil dan memiliki persentase tetas sebesar $10 \%$. Hasil tersebut tidak sesuai antara sistem dengan kondisi telur sebenarnya. Ketidaksesuaian tersebut terjadi karena cangkang telur memiliki bercak, dengan memberikan nilai $\mathrm{T}$ sebesar 55 membuat bercak tersebut terdeteksi. Untuk mengatasinya dapat dilakukan dengan mengubah-ubah nilai T yang digunakan.

\section{c. Hasil Uji Coba Ketiga}

Selanjutnya, di bawah ini merupakan hasil uji coba identifikasi citra telur ketiga menggunakan nilai T sebesar 45 .

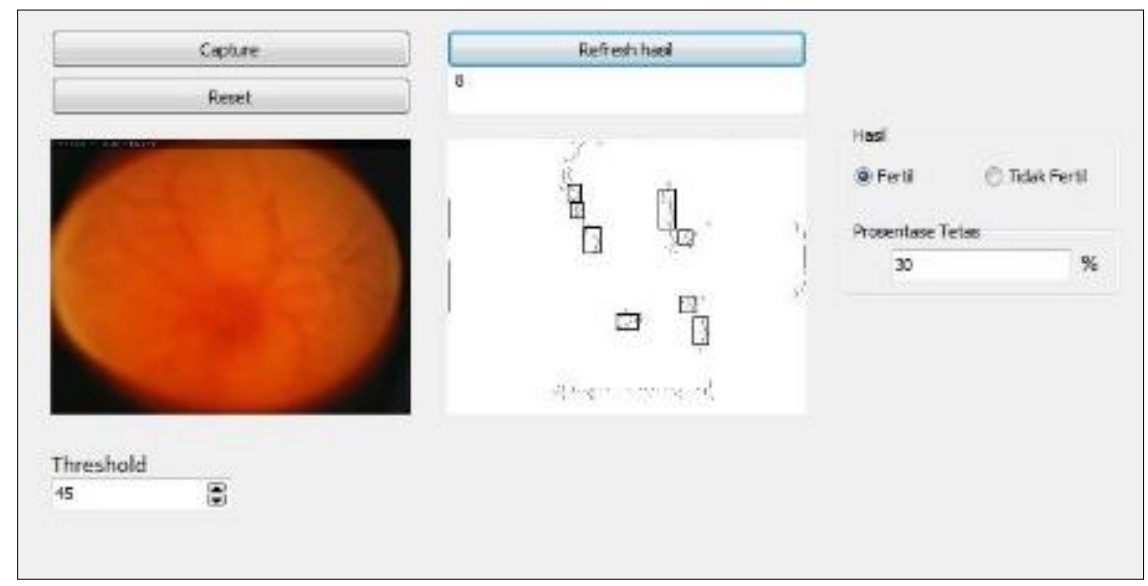

Gambar 5. Tampilan hasil pada GUI

Dari gambar di atas dapat diketahui bahwa kondisi telur sebenarnya terdapat embrio tumbuh didalamnya (fertil). Dengan input $\mathrm{T}=45$, sistem dapat mendeteksi adanya embrio di dalam telur, sehingga hasilnya adalah fertil. Hasil pada GUI dengan $\mathrm{T}=45$, maka kontur objek mendeteksi 8 titik yang dianggap sebagai embrio dengan menandainya dengan kotak kecil. Dari jumlah tersebut dijadikan sebagai acuan penentuan perkiraan presentase tetasnya. 
d. Hasil Uji Coba Keempat

Di bawah ini merupakan hasil identifikasi pada citra telur dengan T sebesar 65 .

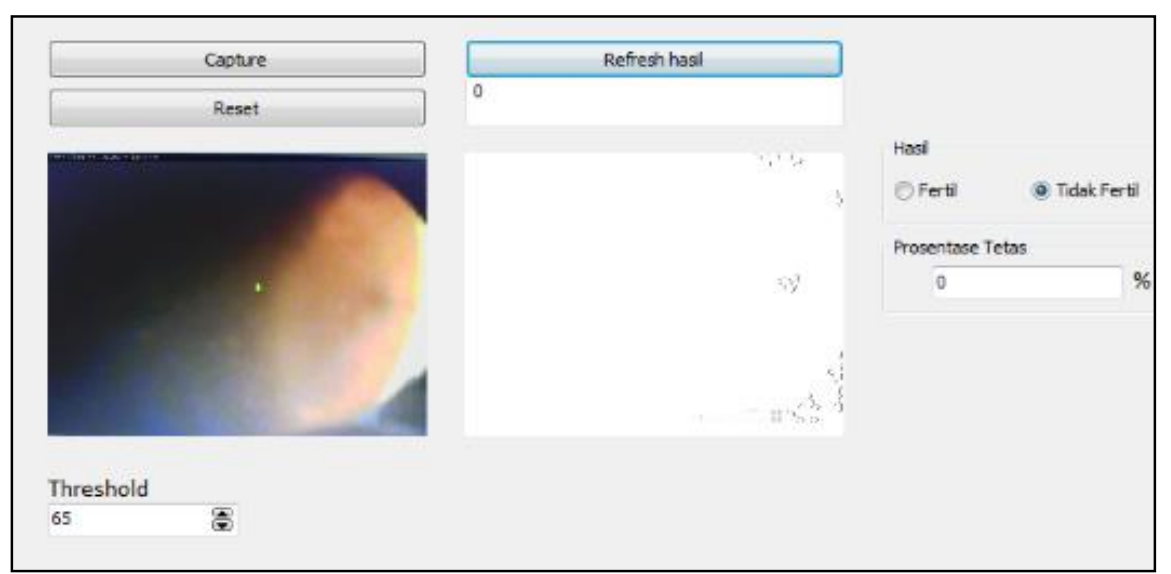

Gambar 6. Tampilan hasil pada GUI

Dapat dilihat bahwa kondisi asli telur adalah fertil dengan titik embrio didalamnya. Dengan nilai $\mathrm{T}$ sebesar 65 maka titik embrio tersebut ikut tersegmentasi dan tidak terdeteksi jumlahnya dan membuat hasil identifikasi menjadi infertil. Untuk mengatasinya dapat dilakukan dengan mengubah nilai $\mathrm{T}$ dapat dinaik atau turunkan. Berikut contoh hasil dengan menurunkan nilai $\mathrm{T}$.

\section{e. Hasil Uji Coba Kelima}

Selanjutnya di bawah ini merupakan hasil identifikasi pada GUI dari perubahan nilai $\mathrm{T}$ yang dilakukan. Objek telur yang digunakan sama dengan percobaan keempat hanya saja menggunakan nilai $\mathrm{T}$ yang berbeda.

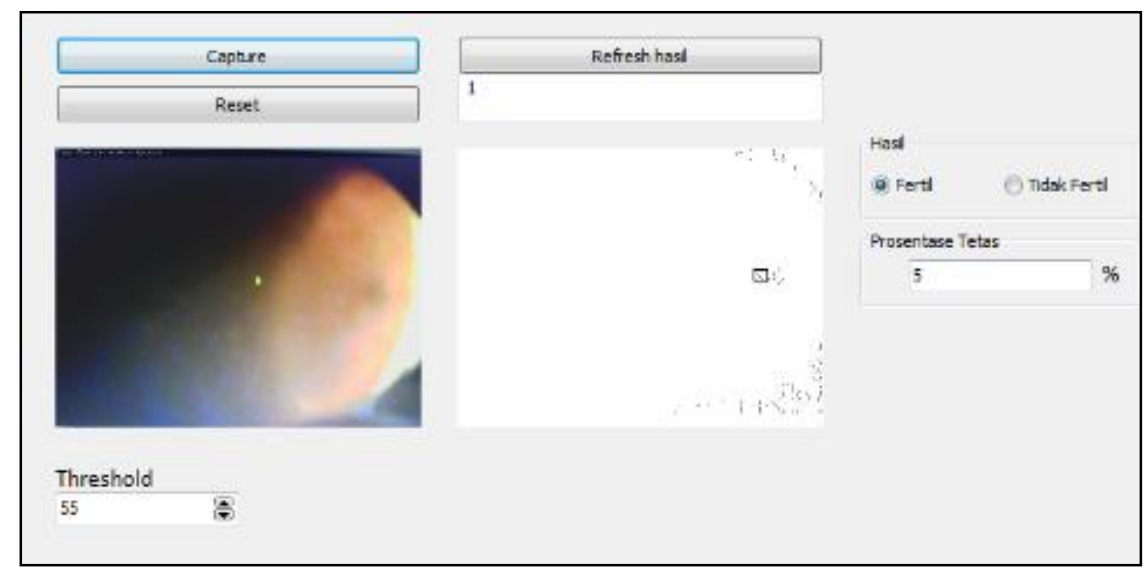

Gambar 7. Tampilan hasil pada GUI

Dengan menurunkan nilai $\mathrm{T}$ menjadi 55, sistem dapat mendeteksi adanya titik embrio dan mensegmentasinya. Kemudian, kontur objek menandai titik tersebut dengan tanda kotak dan menjadi acuan penentuan hasil kategori yakni fertil serta besarnya nilai perkiraan persentase tetas yakni sebesar $5 \%$. Semakin banyak kontur objek menandai objek yang dianggap sebagai embrio, maka semakin besar pula perkiraan persentase tetasnya. 


\section{KESIMPULAN}

Dari percobaan yang telah dilakukan dapat diambil kesimpulan bahwa besar nilai threshold $\mathrm{T}$ yang digunakan memiliki pengaruh besar pada hasil segmentasi atau citra biner yang diperoleh. Karena dari citra biner inilah dasar proses pengolahan citra selanjutnya. Jika nilai $\mathrm{T}$ yang digunakan tepat, maka hasil kategori (fertil/infertil) yang diperoleh akan sesuai antara kondisi telur asli dengan sistem. Begitupun dengan besarnya nilai perkiraan persentase tetas antara kondisi asli telur dengan sistem (dilihat dari banyak pembuluh darah embrio). Namun tidak selalu besar nilai perkiraan persentase tetas antara sistem dan kondisi asli memiliki nilai sama. Karena beberapa faktor diantaranya adalah kondisi cangkang yang kotor atau memiliki bercak yang dapat diidentifikasi sistem sebagai embrio jika pemilihan nilai T kurang tepat. Selain dari nilai $\mathrm{T}$ dan kondisi telur, faktor lain yang dapat mempengaruhi hasil identifikasi adalah perangkat yang digunakan seperti tingkat kecerahan senter atau lampu serta kualitas webcam yang digunakan.

Kemudian untuk kesesuaian antara kondisi telur yang sebenarnya dengan hasil yang diperoleh pada sistem identifikasi memiliki persentase keberhasilan sebagai berikut.

a. $88.8 \%$ pada hasil penentuan kategori telur (fertil/infertil)

b. $61.11 \%$ pada perkiraan persentase tetas telur

Untuk pemilihan metode pengolahan citra sendiri penggunaannya harus disesuaikan dengan kondisi objek yang di proses. Bisa jadi penggunaan metode yang tidak terlalu banyak seperti menghilangkan proses penipisan gambar (thinning), dikarenakan objek berupa pembuluh darah atau embrio pada telur sendiri terkadang memiliki sifat yang tipis dan samar terlihat. Jadi hasil yang didapatkan bisa jadi lebih maksimal.

\section{REFERENSI}

[1] D. A. N. Komunikasi, "FITUR WARNA DAN BENTUK FERTILE AND INFERTILE EGG CLASSIFICATION USING MULTI LAYER PERCEPTRON NEURAL NETWORK BASED ON COLOUR AND SHAPE FEATURE EXTRACTIONS,” vol. 4, no. 2, pp. 100-109, 2015.

[2] S. Saifullah, Sunardi, and A. Yudhana, "Analisis Ekstraks Ciri Fertilitas Telur Ayam Kampung Dengan," J. Nas. Tek. Elektro, vol. 6, no. 2, pp. 67-75, 2017, doi: 10.20449/jnte.v6i2.376.

[3] A. Sindar and R. M. Sinaga, "DIGITAL," vol. 1, no. 2, pp. 48-51, 2017.

[4] P. Kendaraan, B. Di, and J. Raya, "Pengolahan citra dengan menggunakan web cam pada kendaraan bergerak di jalan raya," vol. 1, pp. 1-6, 2016.

[5] D. A. Priandini, J. Nangi, M. Muchtar, and J. Y. Sari, "Deteksi area plat mobil menggunakan operasi morfologi citra," Semin. Nas. Teknol. Terap. Berbas. Kearifan Lokal, pp. 294-302, 2018.

[6] S. Pengajar, T. Elektro, and P. Negeri, “Algoritma image thinning," pp. 29-37.

[7] R. Hamid, "Rancang Bangun Robot Pengangkat Box Berbasis Mikrokontroler ATmega16," 2017.

[8] H. Al Fatta, "KONVERSI FORMAT CITRA RGB KE FORMAT GRAYSCALE MENGGUNAKAN VISUAL BASIC," vol. 2007, no. November, pp. 1-6, 2007.

[9] R. D. Kusumanto and A. N. Tompunu, "PENGOLAHAN CITRA DIGITAL UNTUK MENDETEKSI OBYEK MENGGUNAKAN PENGOLAHAN WARNA MODEL NORMALISASI RGB,” vol. 2011, no. Semantik, 2011.

[10] F. A. Fakhrina, "THINNING ZHANG - SUEN DAN STENTIFORD UNTUK MENENTUKAN EKSTRAKSI CIRI ( MINUTIAE ) SEBAGAI IDENTIFIKASI POLA SIDIK JARI WHORL DAN LOOP," vol. 15, no. 2, pp. 127-133, 2016. 


\section{BIOGRAFI PENULIS}

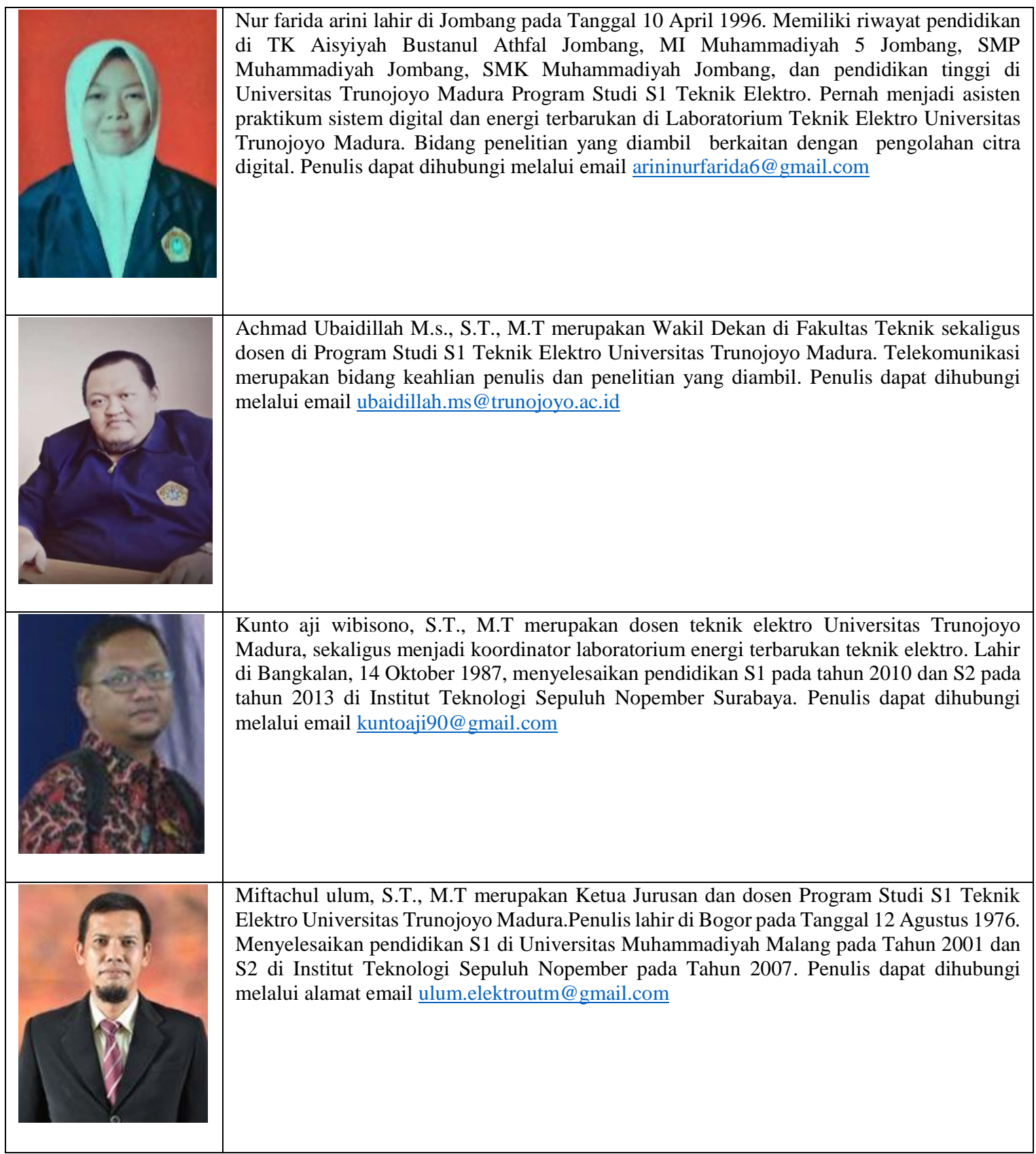

